\title{
Synthesis and Application of Arylaminophosphazene as a Flame Retardant and Catalyst for the Polymerization of Benzoxazines
}

\author{
Natalia V. Bornosuz ${ }^{1}$, Irina Yu. Gorbunova ${ }^{1}$, Vyacheslav V. Kireev ${ }^{1}$, Yulya V. Bilichenko ${ }^{1}$, Larisa V. Chursova ${ }^{2}$, \\ Yuri S. Svistunov ${ }^{3}$, Denis V. Onuchin ${ }^{1}$, Vyacheslav V. Shutov ${ }^{1}$, Viktoria V. Petrakova ${ }^{1}$, Alexander A. Kolenchenko ${ }^{1}$, \\ Duong T. Nguyen ${ }^{1}$, Nikolay V. Pavlov ${ }^{1}$, Alexey V. Orlov ${ }^{2}$, Tatyana A. Grebeneva ${ }^{2}$ and Igor S. Sirotin ${ }^{1, *(D)}$ \\ 1 Mendeleev University of Chemical Technology of Russia, 125047 Moscow, Russia; \\ bornosuz@muctr.ru (N.V.B.); igorbunova@muctr.ru (I.Y.G.); kireev@muctr.ru (V.V.K.); \\ bilichenko@muctr.ru (Y.V.B.); donuchin@muctr.ru (D.V.O.); shutov1105@gmail.com (V.V.S.); \\ vvvorobeva@muctr.ru (V.V.P.); kolenchenkoalex@muctr.ru (A.A.K.); nguyentanyen2@gmail.com (D.T.N.); \\ npavlov@muctr.ru (N.V.P.) \\ 2 Prepreg-ACM JSC (Part of UMATEX, Rosatom State Corporation), 109316 Moscow, Russia; \\ 1.chursova@umatex.com (L.V.C.); a.orlov@umatex.com (A.V.O.); t.grebeneva@umatex.com (T.A.G.) \\ 3 NPK Khimprominzhiniring, JSC (Part of UMATEX, Rosatom State Corporation), 109316 Moscow, Russia; \\ y.svistunov@umatex.com \\ * Correspondence: isirotin@muctr.ru; Tel.: +7-(499)-978-91-98
}

Citation: Bornosuz, N.V.; Gorbunova, I.Y.; Kireev, V.V.; Bilichenko, Y.V.; Chursova, L.V.; Svistunov, Y.S.; Onuchin, D.V.; Shutov, V.V.; Petrakova, V.V.; Kolenchenko, A.A.; et al. Synthesis and Application of Arylaminophosphazene as a Flame Retardant and Catalyst for the Polymerization of Benzoxazines. Polymers 2021, 13, 263. https:// doi.org/10.3390/polym13020263

Received: 24 December 2020

Accepted: 10 January 2021

Published: 14 January 2021

Publisher's Note: MDPI stays neutral with regard to jurisdictional clai$\mathrm{ms}$ in published maps and institutional affiliations.

Copyright: (C) 2021 by the authors. Licensee MDPI, Basel, Switzerland. This article is an open access article distributed under the terms and conditions of the Creative Commons Attribution (CC BY) license (https:// creativecommons.org/licenses/by/ $4.0 /)$.

\begin{abstract}
A novel type of phosphazene containing an additive that acts both as a catalyst and as a flame retardant for benzoxazine binders is presented in this study. The synthesis of a derivative of hexachlorocyclotriphosphazene (HCP) and meta-toluidine was carried out in the medium of the latter, which made it possible to achieve the complete substitution of chlorine atoms in the initial HCP. Thermal and flammability characteristics of modified compositions were investigated. The modifier catalyzes the process of curing and shifts the beginning of reaction from $222.0^{\circ} \mathrm{C}$ for pure benzoxazine to $205.9^{\circ} \mathrm{C}$ for composition with $10 \mathrm{phr}$ of modifier. The additive decreases the glass transition temperature of compositions. Achievement of the highest category of flame resistance (V-0 in accordance with UL-94) is ensured both by increasing the content of phenyl residues in the composition and by the synergistic effect of phosphorus and nitrogen. A brief study of the curing kinetics disclosed the complex nature of the reaction. An accurate two-step model is obtained using the extended Prout-Tompkins equation for both steps.
\end{abstract}

Keywords: benzoxazines; phosphazenes; curing kinetics; flammability; flame retardant; catalysis; m-toluidine

\section{Introduction}

Nowadays, it is impossible to imagine human life without polymer matrix composite materials (PMCs). The unique combination of polymer matrix and filler works together to provide it unique properties; the key among them are high physical and operational characteristics, often exceeding the values of traditional materials (metals and their alloys, wood) in a wide temperature range, with low specific gravity combined with high strength, moisture and chemical resistance, radio transparency, excellent dielectric properties, durability, resistance to significant cyclic loads, etc. [1-3]. The abovementioned properties allowed polymer composite materials to take their place in our daily life; PMCs are used in automotive and shipbuilding industries, aircraft, sports, medical applications and many other fields [4-6]. One of the main disadvantages of most polymers and many composites based on them is their high flammability due to the organic nature of the matrix, which limits wider application of PMCs.

The common way to reduce the flammability of polymer composites is to introduce flame retardants, which can be divided into two groups: additive and reactive [7,8]. Addi- 
tive flame retardants are not capable of chemically binding to the polymer matrix of the composition; therefore, either the phenomenon of exfoliation of the flame retardant or the phase inversion binder-modifier may occur, and, as a result, deterioration of the physical, mechanical and operational properties of products may take place. Reactive, as opposed to additive, flame retardants have functional groups in their structure that can interact with the reaction centers of the binder during the curing process and thereby incorporate into the polymer matrix network. The application of these flame retardants reduces the flammability of the material and could increase mechanical properties.

Phosphorus-containing compounds are widespread flame retardants. Phosphazenebased retardants can be either additive or reactive. The main chain of organophosphazenes consists of alternating phosphorus and nitrogen atoms, and at the phosphorus atom, there are organic radicals introduced by the substitution of halogen in halogen phosphazenes. The nature of organic substituents can vary within wide limits and determines the properties of the resultant polymer. For example, aryloxyphosphazenes, in comparison with other organophosphorus compounds, have higher thermal stability and chemical resistance and are known as fire retardants [8,9], characterized by the synergistic effect of phosphorus and nitrogen [10]. The other example is hexaphenoxycyclotriphosphazene, which is used as a highly effective flame retardant for a large number of synthetic polymers. A number of effective flame-retarded functional epoxy resins, amine curing agents and benzoxazines with a phosphazene core have been proposed [11-21]. Carboxyl-containing epoxyphosphazenes and their use as a catalyst for the polymerization of benzoxazines have also been reported [22].

Benzoxazine monomers, as a novel class of binders, are currently commercialized by many leading manufacturers, such as Huntsman Advanced Materials, Kaneka Aerospace, Gurit, etc. Due to the special molecular structure of benzoxazine and its corresponding outstanding properties, five different types of benzoxazine binders are present in the market for aerospace, electronic or civilian use.

The high curing temperature of benzoxazines is one of the problems that limits their widespread application [23]. The main way to solve this problem is to use catalysts [24-33] such as phenols [24,25], strong acids [26], carboxylic acids [27,28] and Lewis acids [29-33]. All listed compounds are effective catalysts for the homopolymerization of benzoxazines; however, due to their high catalytic efficiency, one cannot use them in a mixture with the most common reactive compounds, such as epoxy resins, since they cause earlier curing of epoxy oligomers, thereby complicating the polymerization of benzoxazine. Among other things, the use of carboxylic acids as catalysts is complicated by the process of decarboxylation at high temperatures, which is accompanied by the release of carbon dioxide, and, as a rule, an increase in the porosity of the composition during curing.

Base catalysts such as amines, imidazoles and organophosphorus compounds, which exhibit a weaker catalyzing effect in comparison with acidic ones, are less applicable. Although commercial polybezoxazines are effective flame retardants in comparison with other polymers, they usually do not reach the UL-94 V-0 rating, so the development of halogen-free flame retardants that are well compatible with base benzoxazine is an urgent task. Variability in the molecular design of phosphazenes allows one to use them as a base of new flame retardants for benzoxazines. However, the known phosphazene components are difficult to synthesize, and, therefore, their industrial applicability may be limited. Thus, the unique properties and widely variable molecular design of organophosphazene allowed us to use it in our work as a base of a flame retardant and catalyst.

This paper describes the synthesis of a new halogen-free phosphorus-containing flame retardant based on hexachlorocyclotriphosphazene and m-toluidine, its effect on the kinetics of thermal curing and the flammability of a benzoxazine polymer. It is assumed that in addition to low flammability, the resulting phosphazene can catalyze the thermal curing of benzoxazines due to the presence of secondary hydrogen atoms in the $\mathrm{m}$-toluidine residue of phosphazene in its structure. 


\section{Materials and Methods}

\subsection{Starting Materials}

Hexachlorocyclotriphosphazene-a white crystalline substance with m.p. of $113^{\circ} \mathrm{C}$; nuclear magnetic resonance (NMR) ${ }^{31} \mathrm{P}$-singlet spectrum with $\delta_{\mathrm{P}}=19.9 \mathrm{ppm}$ was obtained by the method in [34]. M-toluidine (Acros Organics, Geel, Belgium), a colorless liquid, was distilled twice under vacuum before use, b.p. $203-204{ }^{\circ} \mathrm{C}$. Solvents were purified according to known methods, and their physical characteristics corresponded to literature data [35].

\subsection{Synthesis of Hexakis-(3-methylphenylamino)cyclotriphosphazene (PN-mt)}

A three-necked $500 \mathrm{~mL}$ round bottom flask equipped with a top-drive agitator, reflux condenser and an inert gas supply system was charged with $25.00 \mathrm{~g}(0.072 \mathrm{~mol})$ of hexachlorocyclotriphosphazene (HCP) and $247.25 \mathrm{~g}$ of m-toluidine $(2.311 \mathrm{~mol})$. The reaction mixture was refluxed under intensive stirring at a temperature of $100^{\circ} \mathrm{C}$ for $1 \mathrm{~h}$; after that, the temperature was increased to $180^{\circ} \mathrm{C}$ and refluxed for the next $2 \mathrm{~h}$. Then, the excess of $\mathrm{m}$-toluidine was distilled off using a vacuum rotary evaporator. First, the remaining dark gray mass was repeatedly washed with $0.1 \mathrm{M}$ aqueous solution of hydrochloric acid and washed until neutral. The resulting product was dried in a vacuum until a constant mass was achieved. The product was a gray crystalline powder. The yield was $44.02 \mathrm{~g}(80 \%)$.

\subsection{Preparation of Benzoxazine Monomer Based on Bisphenol A, M-Toluidine and Paraphormaldehyde (BA-mt)}

The benzoxazine monomer BA-mt (bis(3-(m-tolyl)-3,4-dihydro-2H-1,3-benzoxazine) was selected as the main component of the composition. It was synthesized using the method reported in the literature [36]. In contrast to the commercially available monomer BA-a (bis (3-phenyl-3,4-dihydro-2H-1,3-benzoxazine)), which has a glass transition temperature of $173^{\circ} \mathrm{C}$, BA-mt is characterized by $217^{\circ} \mathrm{C}$ for completely cured samples by mode $2 \mathrm{~h} 180{ }^{\circ} \mathrm{C}, 4 \mathrm{~h} 200{ }^{\circ} \mathrm{C}, 1 \mathrm{~h} 210^{\circ} \mathrm{C}$.

\subsection{Composition Preparation}

In order to determine the effect of the synthesized phosphazene compound on the flammability and thermal properties of benzoxazine, the compositions presented in Table 1 were prepared and studied.

Table 1. Formulation of mixtures in parts by weight (bpw).

\begin{tabular}{ccc}
\hline Formulation Number & BA-mt $^{\mathbf{1}}, \mathbf{p b w}$ & PN-mt $^{\mathbf{2}}, \mathbf{p b w}$ \\
\hline 1 & 100 & 0 \\
2 & 100 & 10 \\
3 & 100 & 20 \\
4 & 100 & 30 \\
\hline
\end{tabular}

${ }^{1}$ bis(3-(m-tolyl)-3,4-dihydro-2H-1,3-benzoxazine, ${ }^{2}$ hexakis-(3-methylphenylamino)cyclotriphosphazene.

The calculated amount of BA-mt and PN-mt was mixed on a magnetic stirrer at $120^{\circ} \mathrm{C}$ for $10 \mathrm{~min}$ to achieve a uniform distribution of powdered PN-mt in the benzoxazine. Subsequent degassing of the systems was performed at $120^{\circ} \mathrm{C}$ for $15 \mathrm{~min}$ at a residual pressure of $1.0 \mathrm{kPa}$. At the end of the degassing process, the resulting compositions either were used as received for the curing study or were cured at $180^{\circ} \mathrm{C}$ for $6 \mathrm{~h}$ for glass transition and flammability measurements.

\subsection{Measurements}

The ${ }^{1} \mathrm{H},{ }^{31} \mathrm{P}$ and ${ }^{13} \mathrm{C}$ NMR spectra were obtained in DMSO-d6 solutions with a Bruker AV-600 spectrometer (Bruker Corporation, Bremen, Germany) operating at 600, 133 and $81 \mathrm{MHz}$, respectively. The signals, due to the deuterated solvents, were used as internal references. The chemical shifts of the signals were calculated relative to the signals of tetramethylsilane $\left({ }^{1} \mathrm{H},{ }^{13} \mathrm{C}\right)$ and phosphoric acid $\left({ }^{31} \mathrm{P}\right)$, which were used as references. The 
spectra were processed with the help of the MestReNova Lab software package (version 12.0.4, MESTRELAB RESEARCH, S.L, Santiago de Compostela, Spain).

Differential scanning calorimeter DSC 204 F1 Phoenix (Netzsch, Selb, Germany) was used for monitoring the curing kinetics in dynamic mode [37]. The temperature characteristics of the curing and glass transition temperatures of cured samples were determined according to ISO 11357-5:1999 [38] and ISO 11357-2:1999 [39], respectively. The heating rate for all measurements was $10^{\circ} \mathrm{C} / \mathrm{min}$. All tests were performed in the temperature range $50-300{ }^{\circ} \mathrm{C}$ in a nitrogen atmosphere at a rate flow of $50 \mathrm{~mL} / \mathrm{min}$. The weight of the samples ranged from 5 to $10 \mathrm{mg}$. For data processing, Proteus Thermal Analysis version 5.2.1. software (Netzsch, Selb, Germany) was used.

Fourier transform IR (FTIR) spectra were recorded on a Magna-IR-750 spectrometer Nicolet FTIR (Labx, Midland, ON, Canada) Center using KBr pellets. The spectra were processed using the Omnic software version 9.2.8.6 Thermo Fisher Scientific Inc (LabX, Midland, ON, Canada).

An elemental analyzer for sulfur, chlorine, nitrogen and carbon Multi EA 5000 was used.

Flammability tests were carried out in accordance with UL-94 [40]; the size of the samples was $127 \mathrm{~mm} \times 12.7 \mathrm{~mm} \times 2 \mathrm{~mm}$.

\section{Results and Discussion}

One of the main disadvantages of benzoxazines that limits their use is a long and "hard" curing mode, whose temperatures can reach $220^{\circ} \mathrm{C}$. To achieve this temperature, special expensive high-temperature equipment is required in industry, which significantly complicates and increases the cost of benzoxazine binder processing. In practice, the maximum temperature for polymer matrix composite (PMC) molding in manufacturing is about $180^{\circ} \mathrm{C}$ or less.

Thus, it becomes relevant to search for the possibility to reduce the final curing temperature of a new type of phenol-formaldehyde oligomer to a temperature of no more than $180^{\circ} \mathrm{C}$ with the achievement of maximum performance characteristics. That is why $\mathrm{PN}-\mathrm{mt}$ seems to be a unique and the most versatile modifier of its kind.

\subsection{Synthesis and Characteristics of Hexakis-(3-methylphenylamino)cyclotriphosphazene (PN-mt)}

Preparation of PN-mt was carried out according to the following scheme (Figure 1):<smiles>Cc1cccc(NP2(Nc3cccc(C)c3)=NP(Nc3cccc(C)c3)(Nc3cccc(C)c3)=NP(Nc3cccc(C)c3)(Nc3cccc(C)c3)=N2)c1</smiles>

Figure 1. Synthesis of hexakis-(3-methylphenylamino)cyclotriphosphazene.

The obtained product was characterized by ${ }^{31} \mathrm{P},{ }^{1} \mathrm{H}$ and ${ }^{13} \mathrm{C}$ NMR spectroscopy (Figures 2-4), differential scanning calorimetry (Figure 5) and elemental analysis (Table 2).

It can be seen from the ${ }^{31} \mathrm{P}$ NMR spectrum (Figure 2) that all the chlorine atoms in the phosphazene cycle were completely replaced by m-toluidine. Analyzing the ${ }^{1} \mathrm{H}$ NMR spectrum, it can be assumed that the signal of the proton of the amine group is superimposed on the signal of one of the protons of the aromatic ring, giving a singlet of 
double intensity. Thus, we can conventionally assume that the intensity of the signals of the protons of the amine group is equal to 1 and, accordingly, the ratio of protons of the $\mathrm{P}-\mathrm{NH}$ group to methyl protons of $\mathrm{m}$-toluidine is 1:3 as calculated. The structure of radicals in the side chain is also confirmed by the ${ }^{13} \mathrm{C}$ NMR spectrum, which contains signals of all characteristic carbon atoms (Figure 4).

The melting point of $\mathrm{PN}-\mathrm{mt}$, determined by the DSC method as a peak temperature, is $239.4^{\circ} \mathrm{C}$ and presented on the DSC curve (Figure 5). The phase transition is characterized by a significant endothermic effect and equal to $84.8 \mathrm{~J} / \mathrm{g}$.

The results of the element analysis are consistent with theoretical calculations for the content of elements in the resulting compound (Table 2).

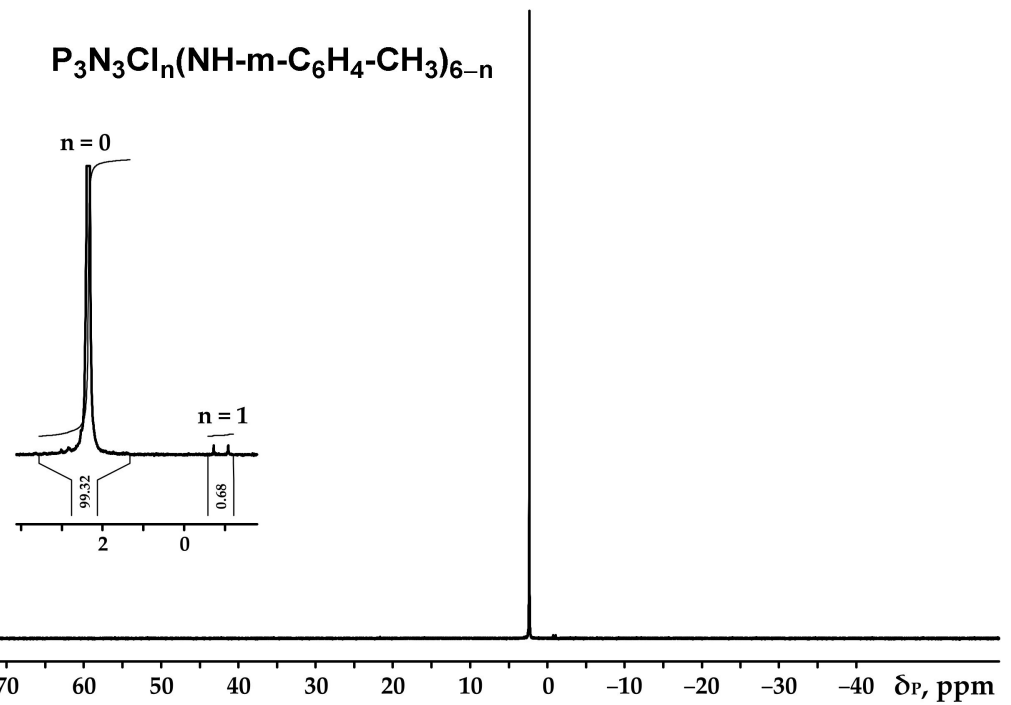

Figure 2. $\mathrm{NMR}^{31} \mathrm{P}$ spectrum of hexa-(m-toluidine)cyclotriphosphazene (PN-mt).

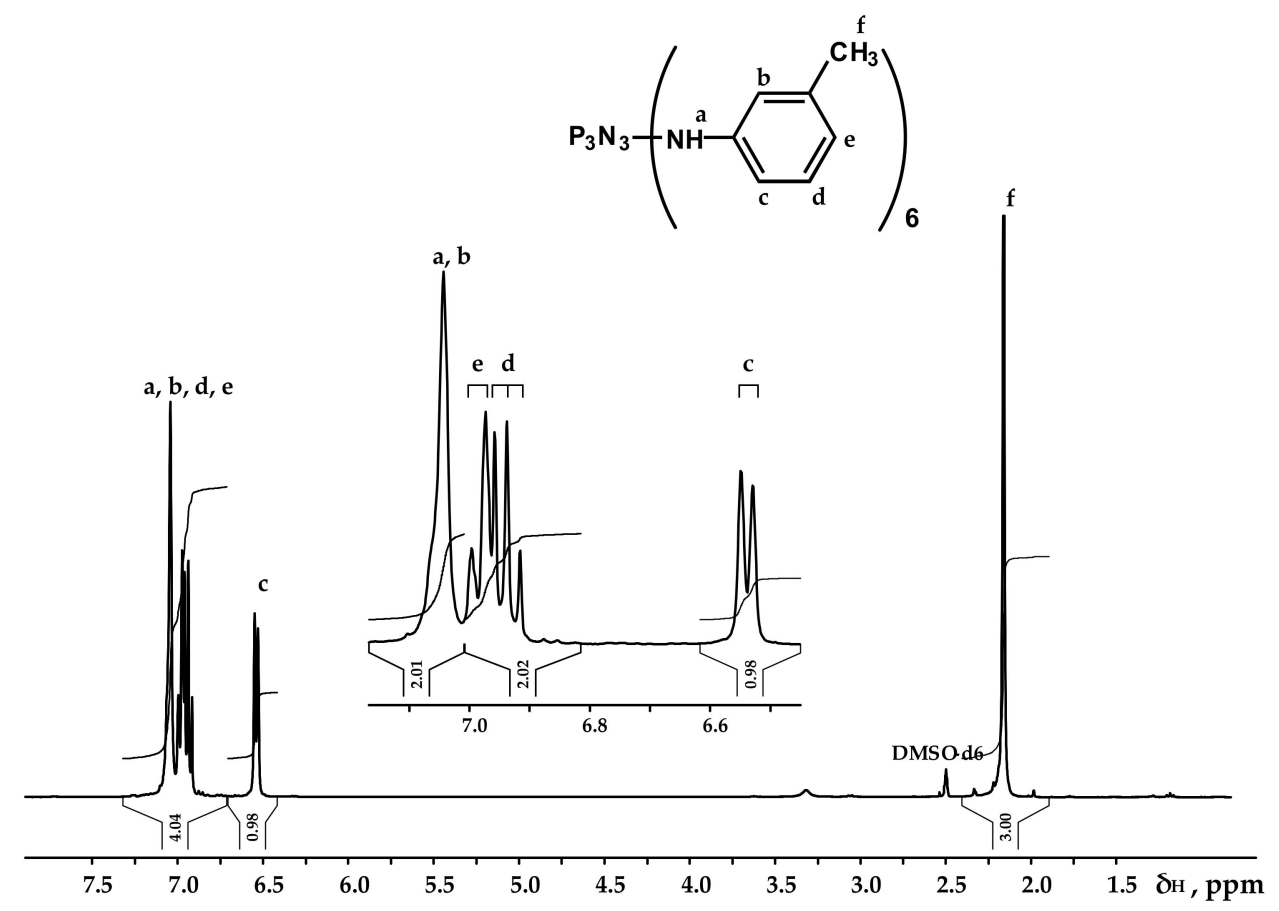

Figure 3. NMR ${ }^{1} \mathrm{H}$ spectrum of PN-mt. 

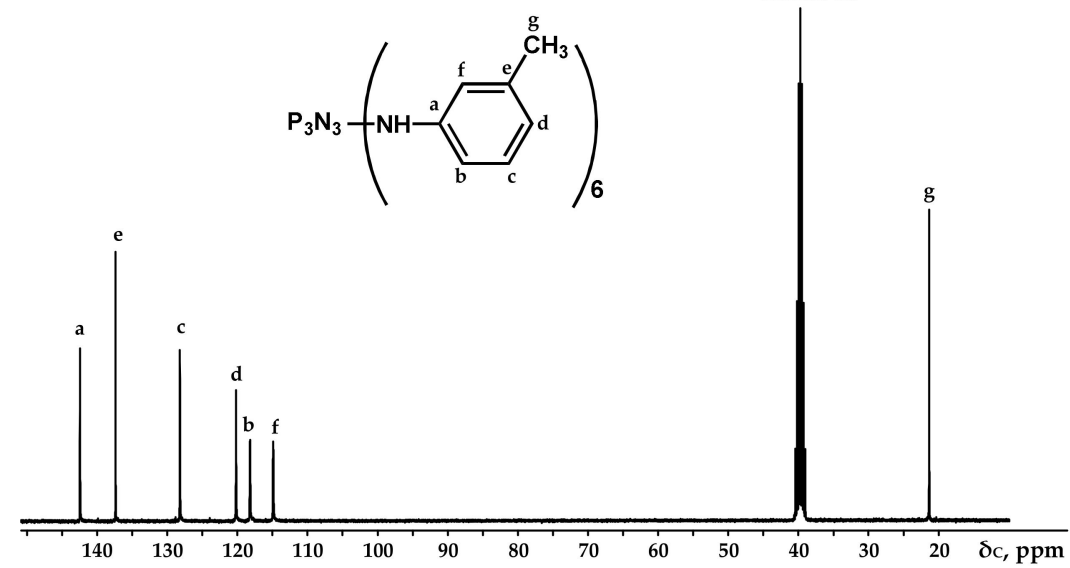

Figure 4. NMR ${ }^{13} \mathrm{C}$ spectrum of $\mathrm{PN}-\mathrm{mt}$.

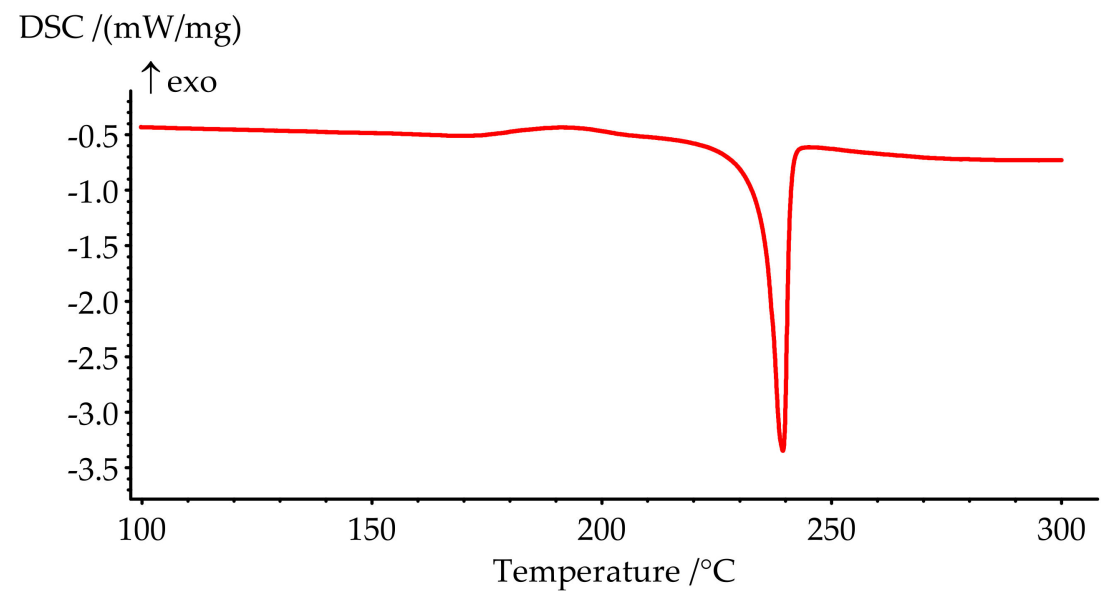

Figure 5. DSC curve of PN-mt melting.

Table 2. Elemental composition of PN-mt.

\begin{tabular}{cccccc}
\hline & $\mathbf{C}, \mathbf{\%}$ & $\mathbf{H}, \mathbf{\%}$ & $\mathbf{N}, \mathbf{\%}$ & $\mathbf{C l}, \mathbf{\%}$ & $\mathbf{P}, \mathbf{\%}$ \\
\hline Calculated & 65.36 & 6.27 & 16.33 & 0 & 12.04 \\
Found & 65.21 & 6.21 & 16.39 & 0 & 12.19 \\
\hline
\end{tabular}

\subsection{Synthesis and Characteristics of BA-mt}

Preparation of BA-mt was carried out according to the following scheme (Figure 6):<smiles>Cc1cccc(N2COc3ccc(C(C)(C)c4ccc5c(c4)CN(c4cccc(C)c4)CO5)cc3C2)c1</smiles>

Figure 6. Synthesis of BA-mt.

The synthesis was carried out in a toluene medium at the temperature of $80-90{ }^{\circ} \mathrm{C}$ with a $10 \%$ excess of paraformaldehyde. The product yield was $95 \%$.

The obtained product was characterized by ${ }^{1} \mathrm{H}$ NMR spectroscopy (Table 3 ) and differential scanning calorimetry (Figure 7, curve 1; Table 4, №1). 
Table 3. The results of ${ }^{1} \mathrm{H}$ NMR spectroscopy of BA-mt.

\begin{tabular}{|c|c|c|c|c|c|}
\hline \multirow{3}{*}{ Sample } & \multicolumn{5}{|c|}{ Proton Chemical Shifts $\delta_{H}(\mathrm{ppm})$} \\
\hline & \multicolumn{2}{|c|}{ Oxazine Ring } & \multirow{2}{*}{$\begin{array}{c}\text { Amine } \\
\mathrm{CH}_{3-}\end{array}$} & \multirow{2}{*}{$\begin{array}{c}\text { Diphenol } \\
\mathrm{CH}_{3}-\end{array}$} & \multirow[b]{2}{*}{$\mathrm{CH}$ (Ar) } \\
\hline & $\mathrm{CH}_{2} \mathrm{~N}$ & $\mathrm{CH}_{2} \mathrm{O}$ & & & \\
\hline BA-mt & 4.56 & 5.30 & 2.30 & 1.57 & $6.62-7.29$ \\
\hline
\end{tabular}

$\mathrm{DSC} /(\mathrm{mW} / \mathrm{mg})$

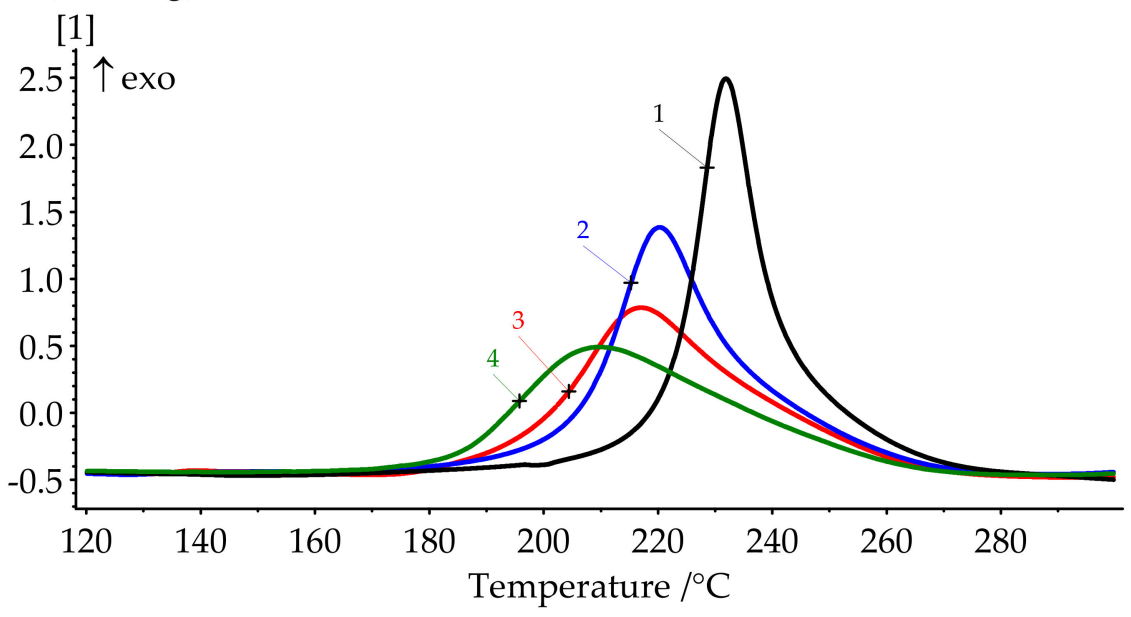

Figure 7. DSC curves of formulations 1-4 cure.

Table 4. Characteristic temperatures of DSC curves of uncured and cured samples for formulations 1-4.

\begin{tabular}{ccccccc}
\hline \multirow{2}{*}{ Formulation № } & \multicolumn{3}{c}{ Uncured Samples (Figure 6) } & \multicolumn{2}{c}{ Cured Samples (Figure 7) } \\
\cline { 2 - 7 } & $\boldsymbol{T}_{\text {onset }},{ }^{\circ} \mathbf{C}$ & $\boldsymbol{T}_{\text {peak }},{ }^{\circ} \mathbf{C}$ & $\boldsymbol{T}_{\text {end }}{ }^{\circ} \mathbf{C}$ & $\Delta \boldsymbol{H}_{\mathbf{~}} \mathbf{~} / \mathbf{g}$ & $\boldsymbol{T}_{\text {g(middle) }}{ }^{\circ} \mathbf{C}$ & $\Delta \boldsymbol{H}_{\text {res }}, \mathbf{J} / \mathbf{g}$ \\
\hline $\mathbf{1}$ & 222.0 & 231.9 & 242.4 & 346.2 & 206.5 & 23.87 \\
$\mathbf{2}$ & 205.9 & 220.3 & 238.2 & 268.6 & 164.9 & 3.18 \\
$\mathbf{3}$ & 195.8 & 217.0 & 247.4 & 260.9 & 162.3 & 0 \\
$\mathbf{4}$ & 184.8 & 209.9 & 255.7 & 252.0 & 160.1 & 0 \\
\hline
\end{tabular}

The ${ }^{1} \mathrm{H}$ NMR spectrum contains signals of the oxazine ring in the region $\delta_{\mathrm{H}}=4.56$ and $5.30 \mathrm{ppm}$, as well as signals of the methyl groups of aromatic amine and bisphenol a in the region $\delta_{\mathrm{H}}=2.30$ and $1.57 \mathrm{ppm}$, respectively.

\subsection{Polymerization of $B A-m t$ in Presence of PN-mt}

Polymerization of BA-mt in the presence of PN-mt was monitored by DSC. Characteristic temperatures of curing and glass transition temperatures of the resulting compositions are presented in Figures 7 and 8 and in Table 4.

DSC results show a significant shift of the onset of curing to the lower temperatures when modifier is added. The catalytic effect is quite explicit. For $10 \mathrm{pbw}$ (formulation 2), this shift appears to be $16.1^{\circ} \mathrm{C}$; for $30 \mathrm{pbw}$ (formulation 4), the apparent shift is $37.2^{\circ} \mathrm{C}$. Here, we can see a decrease in the heat release during curing from $346.2 \mathrm{~J} / \mathrm{g}$ for unmodified BA-mt (formulation 1) to $252.0 \mathrm{~J} / \mathrm{g}$ for $30 \mathrm{pbw}$ (formulation 4). This may be due to the possibility of a nucleophilic attack of the lone electron pair of the nitrogen atom in PN-mt on the methylene bridge connecting the oxygen and nitrogen atoms in the benzoxazine ring (Figure 9). 


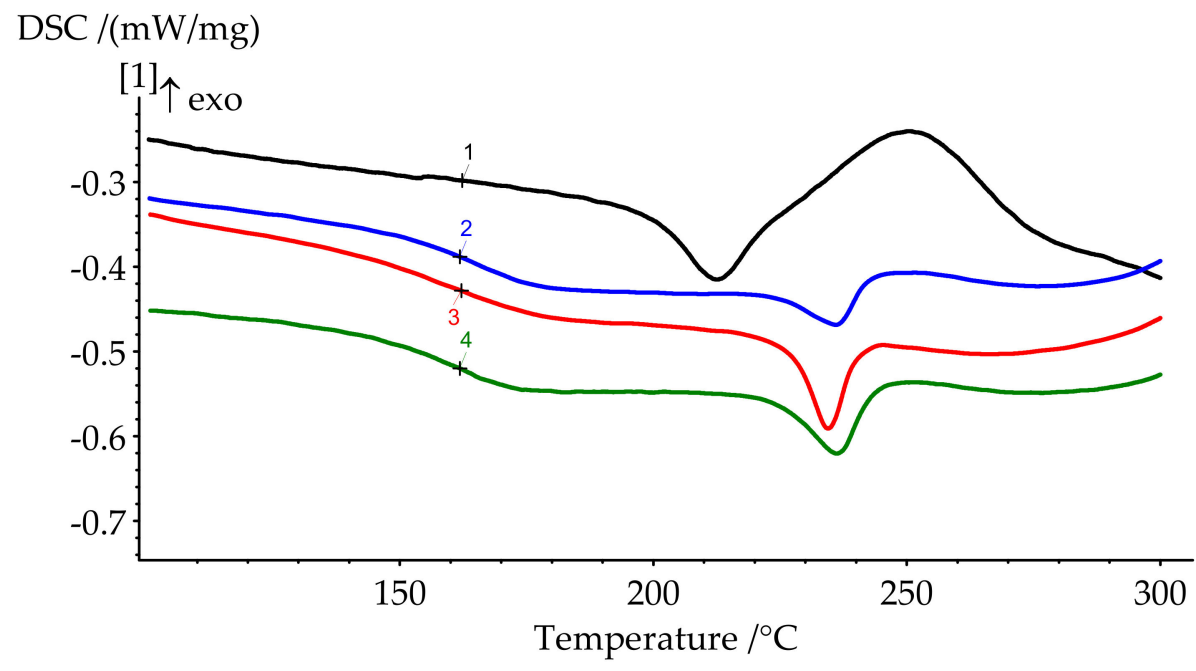

Figure 8. DSC curves of cured formulations 1-4.

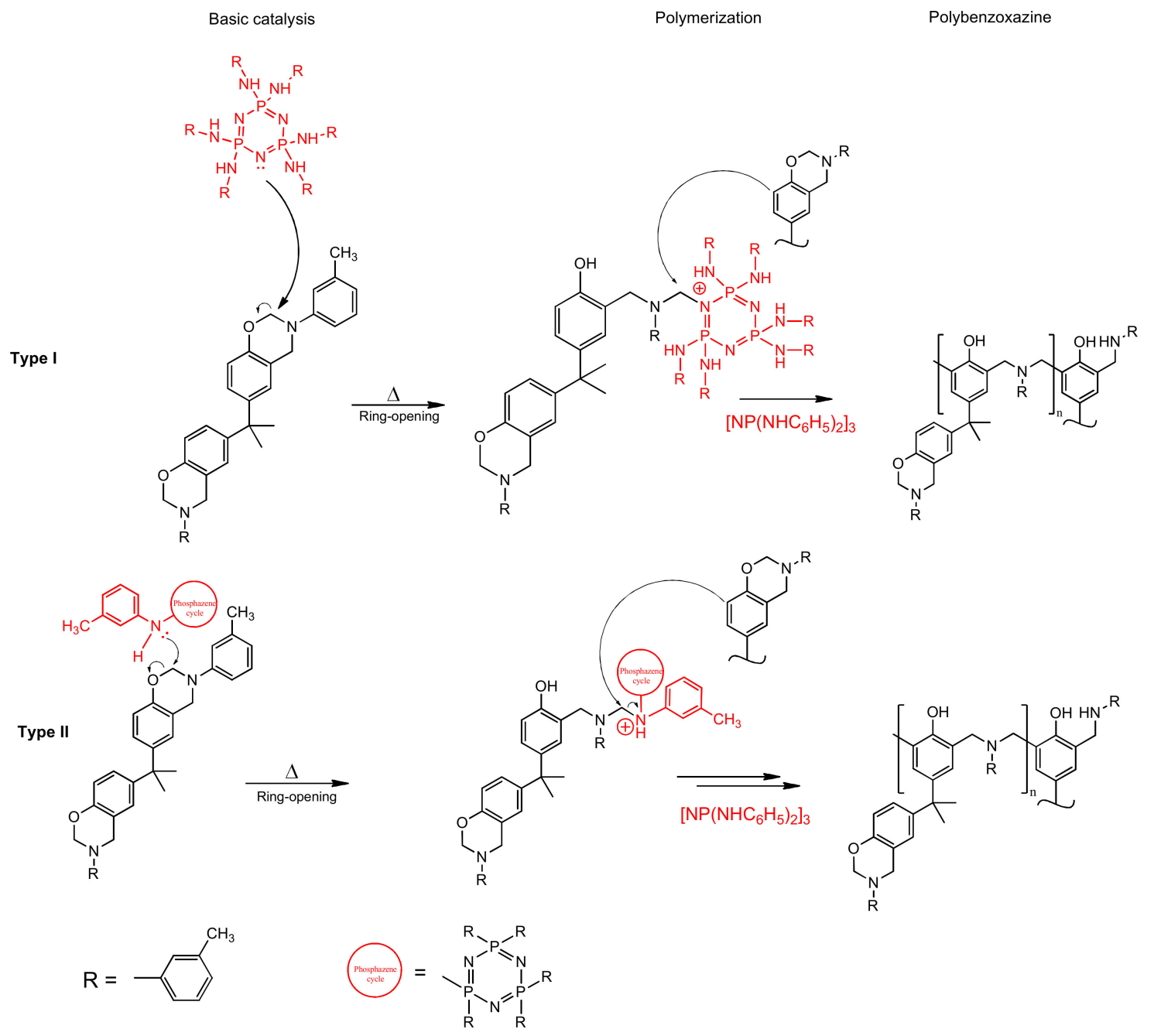

Figure 9. Proposed mechanism of benzoxazine polymerization catalyzed by PN-mt.

The degree of curing under the given conditions increases with an increase in the concentration of PN-mt in the compositions. The presence of residual enthalpy indicates the incomplete cure of compositions. It should be noted that an increase in the concentration of PN-mt in the mixture, starting from $10 \mathrm{pbw}$, leads to the appearance of an endothermic 
peak in the region of $240^{\circ} \mathrm{C}$, corresponding to the melting point of neat PN-mt. It indicates incomplete compatibility of the modifier with the matrix. This is one of the explanations for the significant decrease in the glass transition temperature when more than $10 \mathrm{pbw}$ of $\mathrm{PN}-\mathrm{mt}$ is added to the composition. The glass transition temperature dramatically falls from $206.5^{\circ} \mathrm{C}$ for unmodified composition (formulation 1) to $164.9^{\circ} \mathrm{C}$ for $10 \mathrm{pbw}$ (formulation 2) and does not significantly differ within the modification. The difference in $T_{\mathrm{g}}$ between formulations 2 and 4 is only $4.8^{\circ} \mathrm{C}$.

Another reason for the decrease in the above-described characteristic is the significant size of the modifier molecules, which is comparable to nanoparticles with a diameter of 1-2 nm. It results in a change in the spatial regularity of the formed polybenzoxazine network and a decrease in the number of hydrogen bonds between hydrogen atoms in phenolic groups and nitrogen in polymerized benzoxazines.

Secondly, in contrast to the classical understanding of a catalyst, which only reduces the activation energy of the reaction without being affected by itself, the synthesized PN-mt could be simultaneously both a catalyst and a comonomer that participates in the polymerization of the benzoxazine monomer BA-mt and is then embedded in a threedimensional structure. This effect is associated with the increased reactivity of the ortho and para positions in the m-toluidine substituent of $\mathrm{PN}-\mathrm{mt}$, due to the presence of a methyl substituent in the meta-position, which has an electron-donating effect. This assumption is intended to be investigated more thoroughly in our further study.

DSC curves of cured samples could also indicate the stability of the materials. The heat release at elevated temperatures usually corresponds to the thermal destruction. The slight rise of the heat flow appears at the end of the runs (Figure 8). Thus, we expect materials to be stable approximately up to $300^{\circ} \mathrm{C}$.

The curing process of the composition was also characterized using FTIR spectroscopy. Figure 10 shows the FTIR spectra of the initial flame retardant PN-mt and benzoxazine monomer BA-mt, as well as four samples of cured compositions, both without using a flame retardant and with its addition in various ratios.

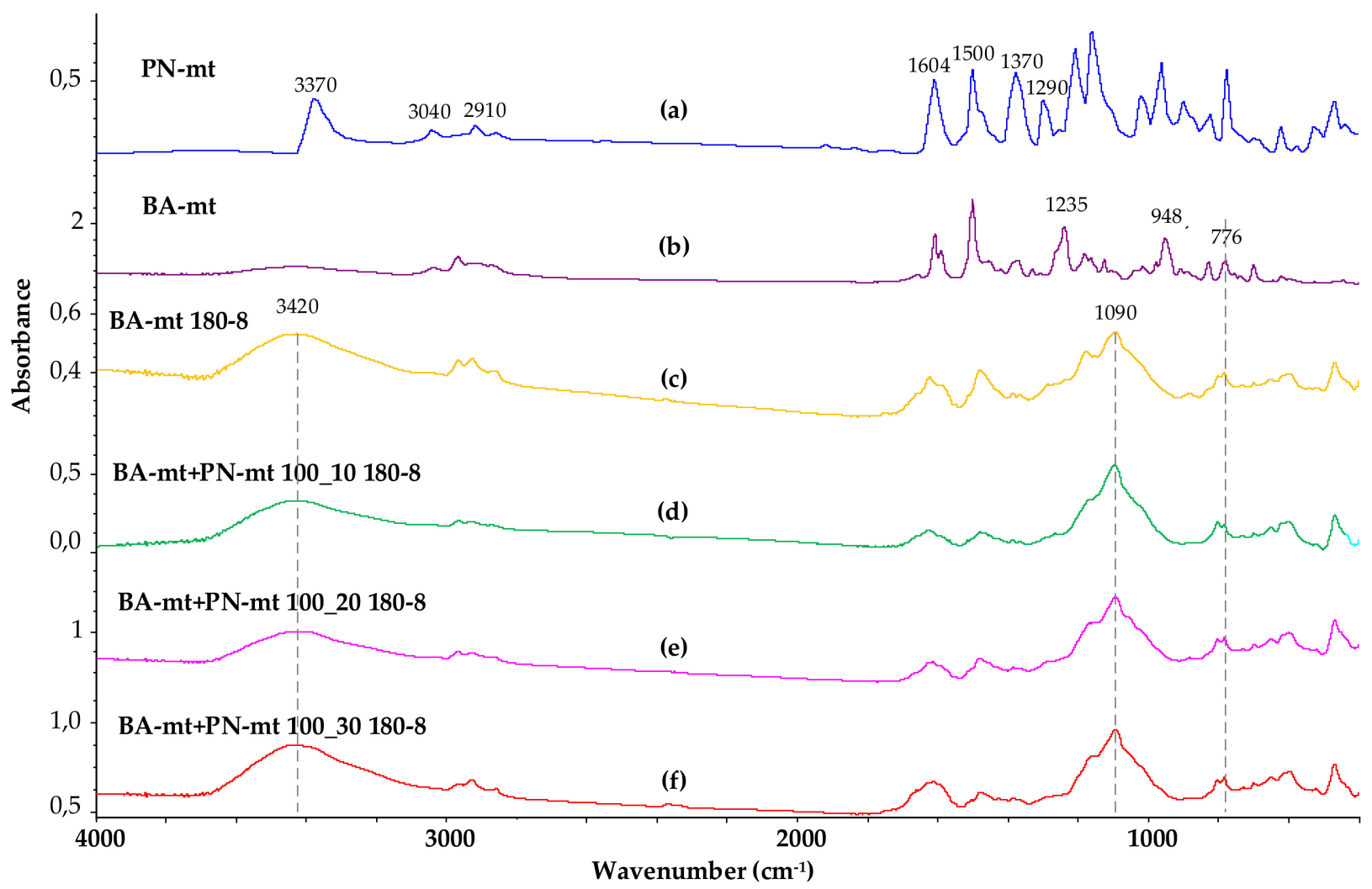

Figure 10. FTIR spectra of PN-mt (a), BA-mt monomer (b), cured BA-mt (c) and cured compositions containing 100 pbw of BA-mt and 10 (d), 20 (e) and 30 (f) pbw of PN-mt. 
Analyzing the FTIR spectrum of the PN-mt compound, we can conclude that it contains all characteristic signals confirming its structure: signals at 1604 and $1290 \mathrm{~cm}^{-1}$ correspond to vibrations of the secondary amino group associated with the benzene ring; signals at 2910 and $1370 \mathrm{~cm}^{-1}$ refer to stretching and bending vibrations, respectively, of methyl groups; signals at 3040, 1600 and $1500 \mathrm{~cm}^{-1}$ are typical for aromatic compounds. The groups of signals responsible for oscillations of the phosphazene cycle are in the range of 700-1200. The signal at 3370 is not entirely clear; it is probably related to the $\mathrm{NH}$ bond of PN-mt.

In the FTIR spectrum of the BA-mt monomer, the signals at 948 and $1235 \mathrm{~cm}^{-1}$ correspond to the stretching vibrations of the C-O-C bond, and at $752 \mathrm{~cm}^{-1}$, to the outof-plane bending vibrations of $\mathrm{Ar}-\mathrm{H}$ in the oxazine ring. In the infrared spectra of the obtained polybenzoxazines, the intensities of these signals are significantly reduced, and a broadened signal appears at 3420 , which corresponds to the stretching vibrations of phenolic hydroxyl groups linked by hydrogen bonds. It should be noted that the addition of a fire retardant to the composition in various amounts practically does not affect the FTIR spectrum. Thus, the data of FTIR spectroscopy do not allow us to make an unambiguous conclusion about the participation of the ortho and para positions of PN-mt in the curing reaction and the formation of covalent bonds between PN-mt and BA-mt. Taking into account the presence of the residual endo-peak on the DSC curves (melting of PN-mt) of the cured modified compositions, it can be concluded that at least part of the modifier is not covalently incorporated into the polymer network.

\subsection{Curing Kinetics}

The common approach to studying curing kinetics is to monitor it by differential scanning calorimetry (DSC), as the crosslinking reaction of thermosetting resins is an exothermic process.

Two main strategies can be used to model the DSC results and derive kinetic laws: model-free and model fitting methods. Model-free isoconversional methods allow us to determine the activation energy as a function of conversion with the simple assumption that "the reaction rate at constant extent of conversion is only a function of temperature", i.e., only for single-step reactions [37]. However, the curing mechanism of thermosetting resins is usually a multi-step one. Particularly, non-negligible contribution of the molecular diffusion might seriously hinder the kinetics of curing [41-43].

The degree of curing is supposed to be proportional to the amount of heat generated during the process and is usually defined as:

$$
\propto(t)=\frac{H(t)}{\Delta H_{\text {total }}}
$$

where $H(t)$ is the accumulative heat of reaction up to a given time $t$ during the curing process; $\Delta H_{\text {total }}$ is the ultimate total heat released at complete cure. For an uncured system, $\alpha=0$, whereas for a completely cured one, $\alpha=1$.

The curing rate is assumed to be proportional to the rate of heat generation $d \alpha / d t$ and is calculated by the following equation:

$$
\frac{d \propto}{d t}=\frac{1}{\Delta H_{\text {total }}} \frac{d H}{d t}
$$

It is currently accepted that the rate of reaction can be defined by two functions, $k(T)$ and $f(\alpha)$ :

$$
\frac{d \propto}{d t}=k(T) f(\propto)
$$

where $d \alpha / d t$ is the reaction rate $\left(\mathrm{s}^{-1}\right), \alpha$ is the degree of conversation (dimensionless), $k(T)$ is the temperature-dependent rate constant, and $f(\alpha)$ is the reaction model. 
The temperature dependence of the reaction rate constant can be represented in the Arrhenius form:

$$
k(T)=A \cdot \exp \left(-\frac{E_{a}}{R T}\right)
$$

In this work, we briefly estimated changes in activation energy during curing for formulation 2 and fitted the reaction model. The kinetic research was based on nonisothermal DSC measurements consisting of three runs with different temperature rates: $5{ }^{\circ} \mathrm{C} / \mathrm{min}, 10^{\circ} \mathrm{C} / \mathrm{min}$ and $20^{\circ} \mathrm{C} / \mathrm{min}$. We used two approaches: model-free isoconversional (Friedman method) and model fitting methods. All calculations were performed in special software, ThermoKinetics 3.1, provided by Netzsch (Selb, Germany).

Activation energy was calculated by the Friedman method [44] consisting of plotting the dependence (5) of the logarithmic Equation (6), where the slope of the linearized curve provided the activation energy. The resulting dependency is represented in Figure 11.

$$
\begin{gathered}
\ln \left(\frac{d \propto}{d t}\right)_{\propto}-(1 / T) \\
\ln \left(\frac{d \propto}{d t}\right)_{\propto}=\ln [A f(\propto)]-\frac{E_{a}}{R T}
\end{gathered}
$$

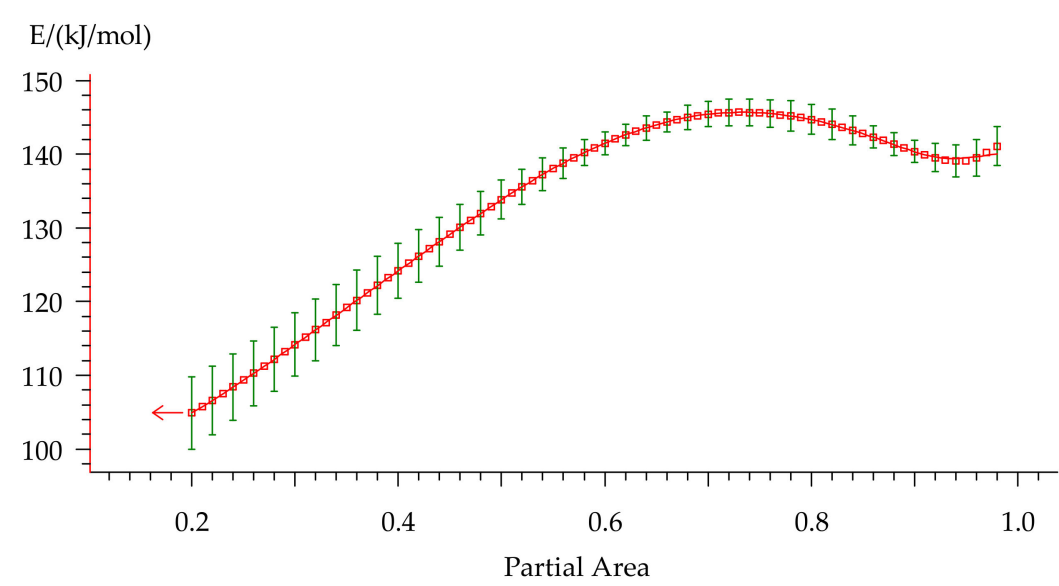

Figure 11. The $E_{a}$-dependency for non-isothermal curing of formulation 2 on the degree of conversion.

Activation energy varies from 105 to $148 \mathrm{~kJ} / \mathrm{mol}$ during the curing process that indicates multiple-stage cure kinetics. This type of $E_{a}$-dependency could describe either two parallel independent reactions or two competitive reactions. Presence of the peak contributes to independent reactions. However, a constant rise of $\mathrm{E}_{\mathrm{a}}$ is usually attributed to competitive reactions. Furthermore, a monotonic change in the peak area that is observed with variation of the heating rate (Table 4) is sufficient evidence of the presence of competitive reactions. As for the small rise of $E_{a}$ at the final stage of curing, we suppose that it could be related to the diffusion control because this behavior is quite typical for this process and was discussed in many works $[41,45,46]$.

In the case of the model fitting approach, we did not obtain an accurate approximation using single-step modeling. This fact is well correlated with the abovementioned results of the Friedman method. Therefore, we decided to separate peaks, calculate their kinetic parameters separately and, after that, combine them into a united two-step scheme model. This method is well discussed by Tikhonov in his study [47].

We separated peaks in Fityk software (Institute of High Pressure Physics, Warsaw, Poland). A typical graphic of separated peaks for formulation 2 is presented in Figure 12. The attempt to utilize the competitive reaction scheme, predicted by isoconversional 
analysis, did not succeed. Only the usage of the consecutive reaction scheme resulted in a quite accurate model of curing. Figure 13 shows the final model fitting for composition 2.

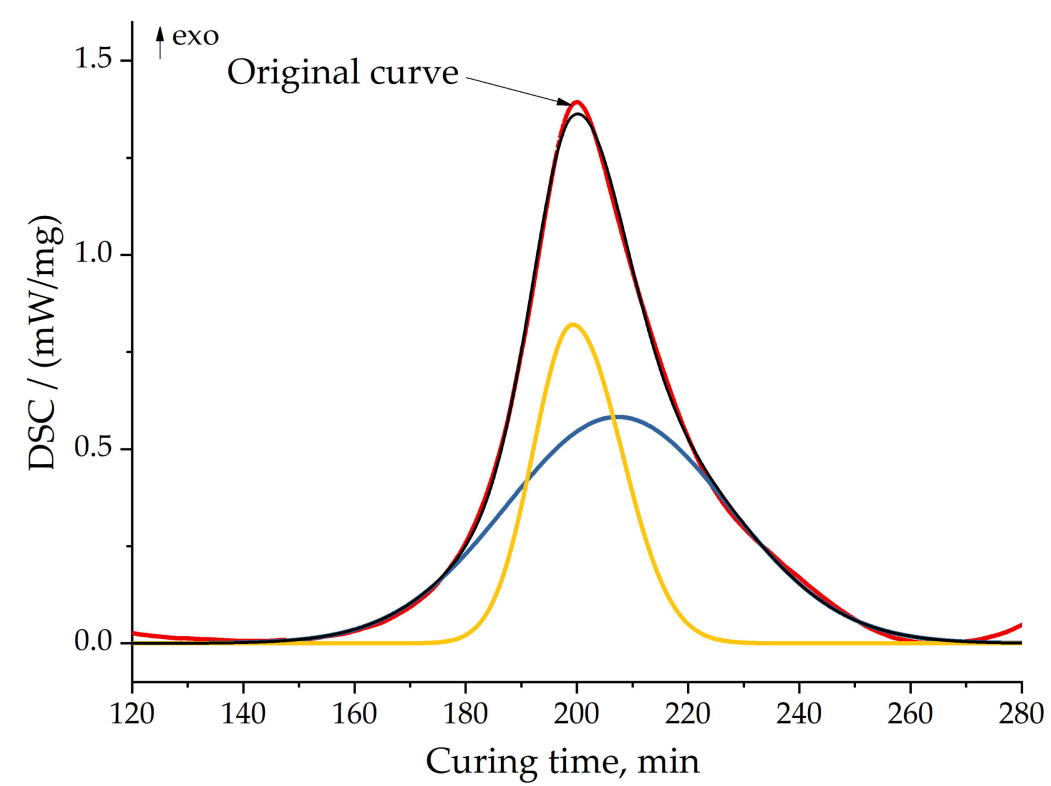

Figure 12. Peak separation for formulation 2 at $10^{\circ} \mathrm{C} / \mathrm{min}$. Red line-original curve; yellow and blue lines—separated peaks; black line-model (sum) of separated peaks.

Heat flow rate/(W/g)

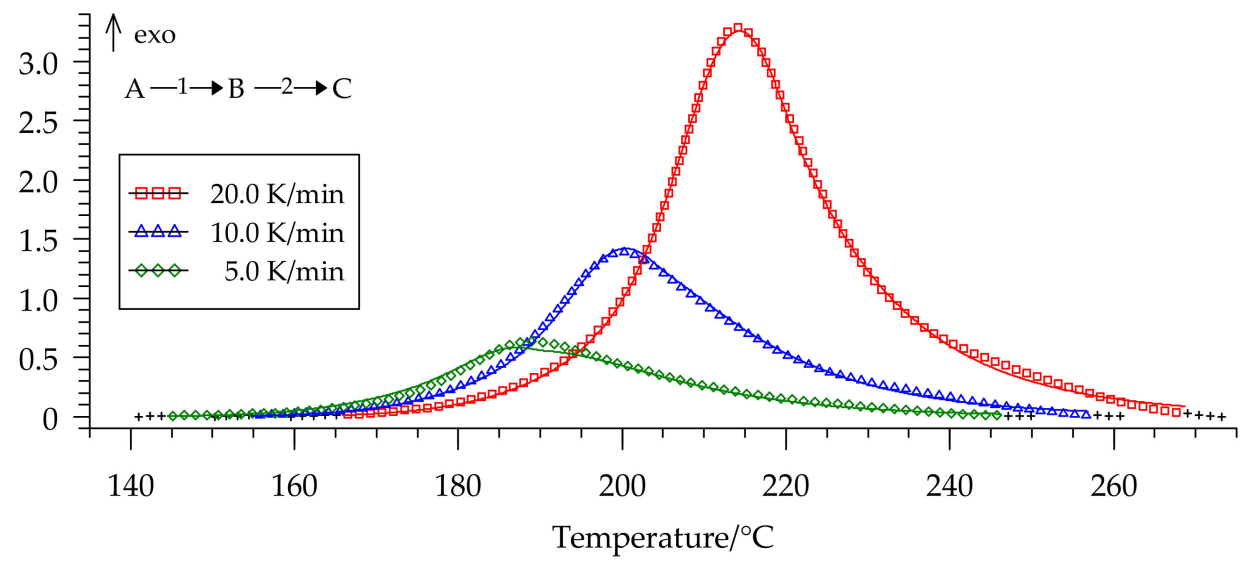

Figure 13. Comparison of experimental (symbols) and calculated (full lines) DSC curves for formulation $2:(\square) 20^{\circ} \mathrm{C} / \mathrm{min}$, $(\Delta) 10^{\circ} \mathrm{C} / \mathrm{min},(\diamond) 5^{\circ} \mathrm{C} / \mathrm{min}$.

The most appropriate type of reaction for two steps appeared to be the extended Prout-Tompkins model:

$$
\begin{gathered}
f(\propto)=(1-\propto)^{n} \propto^{m} \\
\frac{d \propto}{d t}=\mathrm{A} \cdot \exp \left(\frac{-E_{a}}{R T}\right)(1-\propto)^{n} \propto^{m}
\end{gathered}
$$

All parameters for the model are presented in Table 5. 
Table 5. Parameters for resulting two-step model for formulation 2.

\begin{tabular}{cc}
\hline Parameter & Optimum Value \\
\hline $\log \mathrm{A}_{1}\left[\mathrm{~s}^{-1}\right]$ & 7.3632 \\
$\mathrm{E}_{1}[\mathrm{~kJ} / \mathrm{mol}]$ & 80.7604 \\
React. Ord. 1 & 0.6224 \\
Exponent $\mathrm{a}_{1}$ & 0.5311 \\
Log $\mathrm{A}_{2}\left[\mathrm{~s}^{-1}\right]$ & 13.2443 \\
$\mathrm{E}_{2}[\mathrm{~kJ} / \mathrm{mol}]$ & 137.0854 \\
React. Ord. 2 & 2.0102 \\
Exponent $\mathrm{a}_{2}$ & 0.0938 \\
Foll. React. 1 & 0.1963 \\
$\mathrm{Correlation} \mathrm{coefficient}$ & 0.9993 \\
$\Delta \mathrm{H}\left(5^{\circ} \mathrm{C} / \mathrm{min}\right), \mathrm{J} / \mathrm{g}$ & 278.7 \\
$\Delta \mathrm{H}\left(10^{\circ} \mathrm{C} / \mathrm{min}\right), \mathrm{J} / \mathrm{g}$ & 268.6 \\
$\Delta \mathrm{H}\left(20^{\circ} \mathrm{C} / \mathrm{min}\right), \mathrm{J} / \mathrm{g}$ & 257.5 \\
\hline
\end{tabular}

A brief kinetics study revealed the complex nature of the curing process of modified composition 2 and proved that this process is not a single step one. The resulting kinetic model of curing was built using a two-step scheme of consecutive reactions and extended Prout-Tompkins model. These facts may indicate that the formation of new bonds between monomers can occur with the participation of different reaction sites both in the aromatic rings of the diphenol and amine residues, and probably the aromatic residue in arylaminophosphazene as well.

\subsection{Flammability}

To estimate the flammability of the resultant cured samples, we used the UL-94 standard.

The content of more than $10 \mathrm{pbw}$ of FR-mt in the composition allows us to achieve the V-0 flammability category of the UL-94 standard. Achievement of the highest category of flame resistance is ensured both by increasing the content of phenyl residues in the composition and by the synergistic effect of phosphorus and nitrogen introduced into the mixture. The results are shown in Table 6.

Table 6. Flammability test results according to UL-94 standard.

\begin{tabular}{cccccc}
\hline Formulation № & $\tau_{\mathbf{1}}, \mathbf{c}$ & $\tau_{\mathbf{2}}, \mathbf{c}$ & $\tau_{\mathbf{3}}, \mathbf{c}$ & $\Sigma_{\boldsymbol{\tau}}, \mathbf{c}$ & UL-94 \\
\hline 1 & 16 & 19 & 14 & 49 & V-1 \\
2 & 5 & 6 & 9 & 20 & V-0 \\
3 & 3 & 5 & 7 & 15 & V-0 \\
4 & 1 & 4 & 5 & 10 & V-0 \\
\hline
\end{tabular}

\section{Conclusions}

From the example of the compositions based on bis(3-(m-tolyl)-3,4-dihydro-2H-1,3benzoxazine (BA-mt), it was found that hexakis-(3-methylphenylamino)cyclotriphosphazene catalyzes polymerization and, at a content of 10 parts by weight or more, increases the fire resistance rating to the UL- $94 \mathrm{~V}-0$ category. The addition of $10 \mathrm{pbw}$ decreases the onset temperature of curing from $222.0^{\circ} \mathrm{C}$ for neat BA- $\mathrm{mt}$ to $205.9^{\circ} \mathrm{C}$. Due to this reduction, it became possible to proceed to complete curing at temperatures up to $180{ }^{\circ} \mathrm{C}$. DSC curves of cured samples revealed the presence of some undissolved particles of PN-mt in compositions, which could be one of the reasons for the dramatic decrease in glass transition temperature from $206.5^{\circ} \mathrm{C}$ (formulation 1) to $160.1{ }^{\circ} \mathrm{C}$ (formulation 4). However, we suppose that this disadvantage could be managed. The study of the kinetics of the curing process revealed signs of two competing reactions in the curing of all compositions and of the neat monomer, which probably relate to the phenolic and amine aromatic reactive sites. 
Author Contributions: Conceptualization, I.Y.G., V.V.K. and Y.S.S.; methodology, Y.V.B.; software, A.V.O.; validation, I.S.S., V.V.P. and A.A.K.; formal analysis, V.V.S.; investigation, T.A.G.; data curation, L.V.C.; writing - original draft preparation, N.V.B.; writing—review and editing, I.S.S.; visualization, N.V.P. and D.T.N.; project administration, D.V.O. All authors have read and agreed to the published version of the manuscript.

Funding: This work was supported by the Ministry of Science and Higher Education of the Russian Federation within the framework of agreement No. 05.604.21.0231; unique identifier of the agreement RFMEFI60419 × 0231.

Institutional Review Board Statement: Not applicable.

Informed Consent Statement: Not applicable.

Data Availability Statement: The data presented in this study are available on request from the corresponding author.

Conflicts of Interest: The authors declare no conflict of interest.

\section{References}

1. Gao, C.; Yu, L.; Liu, H.; Chen, L. Development of Self-Reinforced Polymer Composites. Prog. Polym. Sci. 2012, 37, 767-780.

2. Blanco, I. The Use of Composite Materials in 3D Printing. J. Compos. Sci. 2020, 4, 42.

3. Singh, D.K.; Vaidya, A.; Thomas, V.; Theodore, M.; Kore, S.; Vaidya, U. Finite Element Modeling of the Fiber-Matrix Interface in Polymer Composites. J. Compos. Sci. 2020, 4, 58.

4. Holbery, J.; Houston, D. Natural-Fiber-Reinforced Polymer Composites in Automotive Applications. JOM 2006, 58, 80-86.

5. Elanchezhian, C.; Ramnath, B.V.; Ramakrishnan, G.; Raghavendra, K.S.; Muralidharan, M.; Kishore, V. Review on Metal Matrix Composites for Marine Applications. Mater. Today Proc. 2018, 5, 1211-1218.

6. Eliasson, J.; Sandström, R. Applications of Aluminium Matrix Composites. Key Eng. Mater. 1995, 104-107, 3-36.

7. Kilinc, F.S. Handbook of Fire Resistant Textiles; Textile Institute (Manchester, UK), Ed.; Woodhead Publishing series in textiles; Woodhead Pub: Oxford, UK; Philadelphia, PA, USA, 2013; ISBN 978-0-85709-123-9.

8. Levchik, S.V.; Weil, E.D. A Review of Recent Progress in Phosphorus-Based Flame Retardants. J. Fire Sci. 2006, $24,345-364$. [CrossRef]

9. Lu, S.-Y.; Hamerton, I. Recent Developments in the Chemistry of Halogen-Free Flame Retardant Polymers. Prog. Polym. Sci. 2002, 27, 1661-1712. [CrossRef]

10. Leu, T.-S.; Wang, C.-S. Synergistic Effect of a Phosphorus-Nitrogen Flame Retardant on Engineering Plastics. J. Appl. Polym. Sci. 2004, 92, 410-417. [CrossRef]

11. Sarychev, I.A.; Sirotin, I.S.; Borisov, R.S.; Mu, J.; Sokolskaya, I.B.; Bilichenko, J.V.; Filatov, S.N.; Kireev, V.V. Synthesis of ResorcinolBased Phosphazene-Containing Epoxy Oligomers. Polymers 2019, 11, 614. [CrossRef]

12. Sirotin, I.S.; Sarychev, I.A.; Vorobyeva, V.V.; Kuzmich, A.A.; Bornosuz, N.V.; Onuchin, D.V.; Gorbunova, I.Y.; Kireev, V.V. Synthesis of Phosphazene-Containing, Bisphenol A-Based Benzoxazines and Properties of Corresponding Polybenzoxazines. Polymers 2020, 12, 1225. [CrossRef]

13. Kireev, V.V.; Bilichenko, Y.V.; Borisov, R.S.; Mu, J.; Kuznetsov, D.A.; Eroshenko, A.V.; Filatov, S.N.; Sirotin, I.S. Synthesis of Bisphenol A Based Phosphazene-Containing Epoxy Resin with Reduced Viscosity. Polymers 2019, 11, 1914. [CrossRef]

14. Chistyakov, E.M.; Terekhov, I.V.; Shapagin, A.V.; Filatov, S.N.; Chuev, V.P. Curing of Epoxy Resin DER-331 by Hexakis(4Acetamidophenoxy)Cyclotriphosphazene and Properties of the Prepared Composition. Polymers 2019, 11, 1191. [CrossRef]

15. Terekhov, I.V.; Filatov, S.N.; Chistyakov, E.M.; Borisov, R.S.; Kireev, V.V. Synthesis of Oligomeric Epoxycyclotriphosphazenes and Their Properties as Reactive Flame-Retardants for Epoxy Resins. Phosphorus Sulfur Silicon Relat. Elem. 2017, 192, 544-554. [CrossRef]

16. Tan, Z.-W.; Wu, X.; Zhang, M.; Qiu, J.-J.; Liu, C.-M. Synthesis and Properties of Main-Chain Oligomeric Benzoxazine Precursor Containing Cyclotriphosphazene Units. High Perform. Polym. 2014, 26, 906-913. [CrossRef]

17. Yang, G.; Wu, W.-H.; Wang, Y.-H.; Jiao, Y.-H.; Lu, L.-Y.; Qu, H.-Q.; Qin, X.-Y. Synthesis of a Novel Phosphazene-Based Flame Retardant with Active Amine Groups and Its Application in Reducing the Fire Hazard of Epoxy Resin. J. Hazard. Mater. 2019, 366, 78-87. [CrossRef] [PubMed]

18. Wu, X.; Liu, S.-Z.; Tian, D.-T.; Qiu, J.-J.; Liu, C.-M. Well-Defined Organic-Inorganic Hybrid Benzoxazine Monomers Based on Cyclotriphosphazene: Synthesis, Properties of the Monomers and Polybenzoxazines. Polymer 2011, 52, 4235-4245. [CrossRef]

19. Tan, Z.-W.; Wu, X.; Zhang, M.; Qiu, J.-J.; Liu, C.-M. Performances Improvement of Traditional Polybenzoxazines by Copolymerizing with Cyclotriphosphazene-Based Benzoxazine Monomers. Polym. Bull. 2015, 72, 1417-1431. [CrossRef]

20. Amarnath, N.; Appavoo, D.; Lochab, B. Eco-Friendly Halogen-Free Flame Retardant Cardanol Polyphosphazene Polybenzoxazine Networks. ACS Sustain. Chem. Eng. 2018, 6, 389-402. [CrossRef]

21. Wu, X.; Zhou, Y.; Liu, S.-Z.; Guo, Y.-N.; Qiu, J.-J.; Liu, C.-M. Highly Branched Benzoxazine Monomer Based on Cyclotriphosphazene: Synthesis and Properties of the Monomer and Polybenzoxazines. Polymer 2011, 52, 1004-1012. [CrossRef] 
22. He, J.; Li, X.; Fu, Y.; Zhu, H.; Zhao, G.; Wang, Z. Curing Reaction Mechanism and Heat Resistance Properties of Hexa-(4Carboxyl-Phenoxy)-Cyclotriphosphazene/Bisphenol A Aniline Benzoxazine Blends. J. Appl. Polym. Sci. 2018, 135, 46389. [CrossRef]

23. Liu, X.; Gu, Y. Study on the Volumetric Expansion of Benzoxazine Curing with Different Catalysts. J. Appl. Polym. Sci. 2002, 84, 1107-1113. [CrossRef]

24. Ishida, H.; Rodriguez, Y. Catalyzing the Curing Reaction of a New Benzoxazine-Based Phenolic Resin. J. Appl. Polym. Sci. 1995, 58, 1751-1760. [CrossRef]

25. Espinosa, M.A.; Galià, M.; Cádiz, V. Novel Phosphorilated Flame Retardant Thermosets: Epoxy-Benzoxazine-Novolac Systems. Polymer 2004, 45, 6103-6109. [CrossRef]

26. Dunkers, J.; Ishida, H. Reaction of Benzoxazine-Based Phenolic Resins with Strong and Weak Carboxylic Acids and Phenols as Catalysts. J. Polym. Sci. A Polym. Chem. 1999, 37, 1913-1921. [CrossRef]

27. Andreu, R.; Reina, J.A.; Ronda, J.C. Carboxylic Acid-Containing Benzoxazines as Efficient Catalysts in the Thermal Polymerization of Benzoxazines. J. Polym. Sci. A Polym. Chem. 2008, 46, 6091-6101. [CrossRef]

28. Gamal Mohamed, M.; Hsiao, C.-H.; Luo, F.; Dai, L.; Kuo, S.-W. Multifunctional Polybenzoxazine Nanocomposites Containing Photoresponsive Azobenzene Units, Catalytic Carboxylic Acid Groups, and Pyrene Units Capable of Dispersing Carbon Nanotubes. RSC Adv. 2015, 5, 45201-45212. [CrossRef]

29. Kasapoglu, F.; Cianga, I.; Yagci, Y.; Takeichi, T. Photoinitiated Cationic Polymerization of Monofunctional Benzoxazine. J. Polym. Sci. A Polym. Chem. 2003, 41,3320-3328. [CrossRef]

30. Liu, C.; Shen, D.; Sebastián, R.M.; Marquet, J.; Schönfeld, R. Mechanistic Studies on Ring-Opening Polymerization of Benzoxazines: A Mechanistically Based Catalyst Design. Macromolecules 2011, 44, 4616-4622. [CrossRef]

31. Liu, C.; Shen, D.; Sebastián, R.M.; Marquet, J.; Schönfeld, R. Catalyst Effects on the Ring-Opening Polymerization of 1,3Benzoxazine and on the Polymer Structure. Polymer 2013, 54, 2873-2878. [CrossRef]

32. Wang, Y.-X.; Ishida, H. Cationic Ring-Opening Polymerization of Benzoxazines. Polymer 1999, 40, 4563-4570. [CrossRef]

33. Mhlanga, P.; Hassan, W.A.W.; Hamerton, I.; Howlin, B.J. Using Combined Computational Techniques to Predict the Glass Transition Temperatures of Aromatic Polybenzoxazines. PLoS ONE 2013, 8, e53367. [CrossRef] [PubMed]

34. Sirotin, I.S.; Bilichenko, Y.V.; Suraeva, O.V.; Solodukhin, A.N.; Kireev, V.V. Synthesis of Oligomeric Chlorophosphazenes in the Presence of ZnCl2. Polym. Sci. Ser. B 2013, 55, 63-68. [CrossRef]

35. Riddick, J.A.; Bunger, W.B.; Sakano, T.; Weissberger, A. Organic Solvents: Physical Properties and Methods of Purification. In Techniques of Chemistry, 4th ed.; Wiley: New York, NY, USA, 1986; ISBN 978-0-471-08467-9.

36. Aizawa, T.; Hirai, Y.; Numata, S. Method for Producing Benzoxazine Resin. U.S. Patent 7,041,772, 9 May 2006.

37. Vyazovkin, S.; Burnham, A.K.; Criado, J.M.; Pérez-Maqueda, L.A.; Popescu, C.; Sbirrazzuoli, N. ICTAC Kinetics Committee Recommendations for Performing Kinetic Computations on Thermal Analysis Data. Thermochim. Acta 2011, 520, 1-19. [CrossRef]

38. 14:00-17:00 ISO 11357-5:1999. Available online: https://www.iso.org/cms/render/live/en/sites/isoorg/contents/data/ standard/02/71/27143.html (accessed on 14 January 2021).

39. 14:00-17:00 ISO 11357-2:1999. Available online: https://www.iso.org/cms/render/live/en/sites/isoorg/contents/data/ standard/02/55/25545.html (accessed on 14 January 2021).

40. Horner, A. Aircraft Materials Fire Test Handbook; Federal Aviation Administration (NTIS): Springfield, VA, USA, 2000.

41. Stutz, H.; Mertes, J.; Neubecker, K. Kinetics of Thermoset Cure and Polymerization in the Glass Transition Region. J. Polym. Sci. A Polym. Chem. 1993, 31, 1879-1886. [CrossRef]

42. Deng, Y.; Martin, G.C. Diffusion and Diffusion-Controlled Kinetics during Epoxy-Amine Cure. Macromolecules 1994, $27,5147-5153$. [CrossRef]

43. Van Assche, G.; Van Hemelrijck, A.; Rahier, H.; Van Mele, B. Modulated Differential Scanning Calorimetry: Non-Isothermal Cure, Vitrification, and Devitrification of Thermosetting Systems. Thermochim. Acta 1996, 286, 209-224. [CrossRef]

44. Friedman, H.L. Kinetics of Thermal Degradation of Char-Forming Plastics from Thermogravimetry. Application to a Phenolic Plastic. J. Polym. Sci. C Polym. Symp. 2007, 6, 183-195. [CrossRef]

45. Sbirrazzuoli, N.; Vyazovkin, S. Learning about Epoxy Cure Mechanisms from Isoconversional Analysis of DSC Data. Thermochim. Acta 2002, 388, 289-298. [CrossRef]

46. Salla, J.M.; Ramis, X. Comparative Study of the Cure Kinetics of an Unsaturated Polyester Resin Using Different Procedures. Polym. Eng. Sci. 1996, 36, 835-851. [CrossRef]

47. Tikhonov, N.A.; Arkhangelsky, I.V.; Belyaev, S.S.; Matveev, A.T. Carbonization of Polymeric Nonwoven Materials. Thermochim. Acta 2009, 486, 66-70. [CrossRef] 